\title{
Periodização da língua portuguesa num contexto social: uma contribução para a Sociolinguística histórica ${ }^{1}$
}

\author{
Maria José Carvalho \\ Facultade de Letras da Universidade de Coimbra \\ (Centro de Estudos de Linguística Geral e Aplicada)
}

\begin{abstract}
Resumo:
Neste trabalho, apresentamos algumas considerações de carácter periodológico que possam contribuir para a desagregação dos dois compactos blocos tradicionalmente estabelecidos na história da língua portuguesa -o português arcaico e o português moderno-, em épocas mais nitidamente diferenciadas. Tentou-se aplicar à Linguística histórica alguns princípios e métodos da Sociolinguística actual, procurando evidenciar uma co-variação de dados linguísticos e factores sociais. É, de facto, nossa convicção que para o estabelecimento de uma proposta de periodização da língua portuguesa deverão relacionar-se os factores internos e externos.
\end{abstract}

\section{Palabras chave:}

Sociolinguística histórica, História da Língua Portuguesa, Português arcaico, Mudança linguística, Variação e mudança, Periodização linguística, Morfologia histórica, Periodização do Português.

\begin{abstract}
:
In this work, we introduce some proposals regarding to the periodisation in the Portuguese language which may contribute to a further division of the traditionally established blocks of Early and Modern Portuguese into more distinct and clear time periods. There was an attempt to apply several principles and methods of Sociolinguistics to historical linguistics by focusing clearly on the co-variation of linguistic data and social factors. In fact, we believe that for the purpose of establishing time periods in the Portuguese language, hypothesis which combines internal and external factors should be considered.
\end{abstract}

Key words:

Historical Sociolinguistics, History of the Portuguese Language, Early Portuguese, Language Change, LinguisticVariation and Change, Linguistic Periodisation, Historical Morphology, Periodisation of the Portuguese Language.

1 Este artigo constitui uma versão aumentada de uma comunicação apresentada em língua inglesa ao XVth International Conference on Historical Linguistics, que decorreu em Melbourne (La Trobe University) de 13 a 17 de Agosto de 2001. 


\section{Introdução}

0. Reconstruir fases pretéritas da língua portuguesa, particularmente numa época em que galegos e portugueses mantinham quase intacto o "cordão umbilical" que os uniria, de forma mais ou menos matizada, durante centenas de anos, é uma tarefa morosa e nada fácil para o investigador. Primeiro, porque dos estádios medievos da nossa língua apenas chegou até nós uma parte da documentação; do destino de outras fontes, perdidas na bruma do tempo ou vitimadas por alguma incúria do Homem, nada sabemos. À escassez dos materiais remanescentes disponíveis para análise (cujo corpus nunca será ideal, por razões de ordem prática), acresce o complexo polimorfismo de que se revestiam as scripta ${ }^{2}$, decorrente, essencialmente, das dificuldades que o manejo de uma nova língua criava a notários e escribas inexperientes. Por outro lado, a análise de alguns textos exige reservas. Como se sabe, é inegável o valor documental de algumas fontes de carácter privado que, pela natureza jurídica que, normalmente, assumem e pelo condicionamento espáciotemporal que as viu nascer, são dos mais fidedignos testemunhos para o estabelecimento do cenário periodológico medieval. As dúvidas subsistem, porém, no que respeita aos textos literários, geralmente "estilizados"3 ou trabalhados em função de necessidades métricas e rimáticas, e cujos autor, data e local de redacção, na maior parte das vezes, se desconhecem.

\subsection{Enquadramento teórico-metodológico}

Constitui um dos objectivos deste artigo apresentar os resultados da pesquisa empreendida no processo de reconstrução de quatro aspectos morfológicos da língua do passado, com base num método de aproximação, por via quantitativa, aos dados empíricos fornecidos pelo corpus documental remanescente dos séculos XIII, XIV, XV e primeiros anos do século XVI ${ }^{4}$. Tentou-se aplicar ao estudo da história da língua portuguesa alguns princípios e métodos da Sociolinguística actual, procurando evidenciar uma eventual co-variação de dados linguísticos e factores

2 O termo "scripta" foi criado por Remacle (1948: 24) para se referir às línguas vulgares escritas da Idade Média.

3 Referindo-se às composições poéticas dos cancioneiros, Clarinda de Azevedo Maia salienta as limitações dos mesmos enquanto fontes de conhecimento do galego-português, exprimindo-se deste modo: "trata-se de uma linguagem literária, de feição artística, que resulta de uma estilização e não de uma reprodução da linguagem falada na Galiza e na zona de Entre-Douro-e-Minho" (Maia 1997: 3).

4 O corpus analisado foi, de facto, muito extenso e inclui diversos tipos textuais que integram a documentação portuguesa remanescente compreendida entre os séculos XIII e XVI. Para se ter uma ideia da sua extensão consulte-se a tese de Mestrado da Autora, apresentada à Faculdade de Letras de Coimbra em 1996 e elaborada no âmbito do "Programa Intervenção Operacional Praxis XXI (carvalho 1996). 
sociais, a partir de uma análise descritiva de frequência, com base estatística, em diferentes tipos textuais. Depois de comparados os dados obtidos sobre os quatro fenómenos de morfologia histórica, foram traçados alguns marcos periodológicos importantes, e, uma vez que uma mudança na língua é, normalmente, subsidiária de factores e eventos que lhe são alheios, estabeleceu-se uma relação entre esses períodos e a dinâmica histórico-social que os motivou. Neste sentido, os fenómenos analisados deixam de ter um carácter isolado para passar a ser encarados como "fenómenos linguísticos de conjuntura" ${ }^{5}$, pois a sua cronologia na língua oral deverá ter sido sensivelmente a mesma. É, de facto, nossa convicção que, na esteira da metodologia da história moderna, deverá constituir uma preocupação constante do periodizador da língua tentar captar, sob vários ângulos, as várias “conjunturas linguísticas" por que passou a língua hodierna.

Pensamos, por todos estes motivos, que um reexame da documentação medieval portuguesa à luz deste modelo inovador de integração da óptica do tempo, virá enriquecer os estudos de carácter filológico realizados no início do nosso século, onde, apenas de forma impressionística, afloram algumas considerações de tipo variacionista sobre alguns fenómenos linguísticos. Como observa Suzanne Romaine: "What is needed is a way of combining the rich philological tradition with recent work on quantitative methods, discourse analysis, literacy as well as with historical phonology, syntax, semantics and pragmatics" (Romaine 1988: 1453). Por outro lado, este modelo poderá contribuir, em grande medida, para a superação das aparentes dicotomias sincronia / diacronia e estrutura / mudança.

Tendo em conta a diversificação do corpus analisado e a consequente diferença de proveniências sócio-culturais dos emissores das fontes que o constituem, inseridos necessariamente em mundividências espácio-temporais também heterogéneas, afigura-se importante um confronto entre vários sistemas que, seguramente, coexistiram no espectro sócio-cultural medieval, e que se concretizaram na formação de uma espécie de continuum linguístico, matizado pelas diferenças de níveis sociolinguísticos que a linguagem dos escribas deixou reflectidas.

\subsection{Apresentação dos fenómenos estudados}

O nosso objectivo primordial é, assim, à luz de uma perspectiva sociolinguística histórica, tecer algumas considerações de carácter periodológico que possam contribuir para a desagregação dos dois compactos blocos tradicionalmente estabele-

5 O termo "conjuntura" é muitas vezes usado por V. Magalhães Godinho: "É de esperar, aliás, que os tempos das estruturas, das conjunturas e dos acontecimentos não coincidam [...]"; e numa outra passagem, acrescenta: "as inversões de conjuntura longa também não datam de um ano preciso simultâneamente para todos os produtos ou sectores, levam alguns anos a espraiar-se[...]" (Godinho 1968: 14-15). 
cidos na história da língua portuguesa ${ }^{6}$-o português arcaico e o português moderno-, em épocas mais nitidamente diferenciadas. As quatro variáveis morfológicas seleccionadas são normalmente consideradas pelos estudiosos como fundamentais para uma proposta de periodização da língua portuguesa:

- O morfema número-pessoal -des de formas verbais do tipo cantades, temedes, etc. e a evolução do morfema após a síncope de $-d$-. No português arcaico as formas verbais da $2^{\mathrm{a}}$ pessoa do plural terminavam no morfema número-pessoal -des ou -de (no imperativo), resultado da evolução fonética do sufixo latino -tis ou -te, sofrendo, ao longo desse período, um processo gradual de desaparecimento do $d$ intervocálico, que irá desencadear as regras assimilatórias subsequentes (temedes $>$ temees, p. ex.). A simplificação (crase) das vogais geminadas e a formação da semivogal (temees $>$ temes $>$ temeis ou temees $>$ temeis) são, normalmente, mais tardias, revelando este último processo um resultado idêntico ao português actual.

- As formas participiais em -udo dos verbos da $2^{\mathrm{a}}$ conjugação (temudo, recebudo, etc) e sua substituição por -ido. Trata-se de um outro fenómeno que se considera importante para qualquer tentativa de estabelecimento de uma periodização da língua portuguesa e que diz respeito à evolução das terminações participiais dos verbos em -er, do português antigo ao português moderno. No português arcaico a terminação dos referidos particípios era constituída pela vogal temática $u+d o$ (temudo, p. ex.), que cedo começou a aparecer em variação com $i+d o$ (temido).

- A existência da dupla série (átona e tónica) dos possessivos femininos e a eliminação das formas átonas no português moderno. No português antigo, as formas proclíticas dos actuais pronomes possessivos femininos minha(s), tua $(s)$ e sua $(s)$ apresentavam, de um modo geral, as grafias $m h a(s)$, mia(s) (pronunciadas como uma só sílaba com ditongo crescente: miá(s)), ma (forma contracta, mais rara), $t a(s)$ e $s a(s)$. Com elas coexistiam as dissilábicas mia, mĩa e minha, usadas, geralmente, como pronomes absolutos ou como pronomes adjuntos pospostos a substantivos. Caracterizava-se, assim, o sistema de tais pronomes pela existência desta dupla série, cujo emprego dependia do lugar que uma e outra ocupavam no sintagma. Esta distinção começou a não ser observada a partir de uma determinada altura, acabando as formas minha, tua e sua por ser generalizadas aos dois contextos, tal como no português de hoje.

6 Grandes mestres da periodização da língua portuguesa, como Said Ali, Serafim da Silva Neto, Carolina Michaëlis de Vasconcelos, José Leite de Vasconcelos e Paul Teyssier são unânimes em considerar que o português antigo se estende até princípios do século XVI, altura em que começa a fase moderna. Outros autores, como Pilar Vázquez Cuesta e Maria Albertina M. da Luz, preferem designar de "português clássico" o português que se delineia no século XVI, designação que é também partilhada por Castro (1991: 241). Uma síntese sobre periodização da língua portuguesa é-nos apresentada, de forma crítica, por Maia (1995: 5-11). 
- A alomorfia no plural dos nomes de lexema em - $l$ (após a síncope desta consoante). A queda de /1/ intervocálico, exclusivamente galego-portuguesa, originou o contacto da vogal $e$ do tema com a vogal tónica precedente (ANIMALES $>$ animaes; CRUDELES > cruees; GENTILES > genties / -iis; SOLES > soes, etc.), resultando, posteriormente, o processo de ditongação (ou crase, no caso de $-l$ precedido de $i$ tónico), que se deu nos finais do período arcaico da nossa língua: animais, crueis, gentis, sóis, etc. A terminação latina -iles originou, em posição tónica, -ies, que passou a -iis, reduzindo-se a -is, por actuação das regras da crase. Quando átona, evoluiu para -ees, que mais tarde, "por dissimilação ou devido ao lugar ocupado pelo último $e$, se tornou em -eis" (Nunes 1989: 229). Acontece que na língua arcaica essa distinção não era observada, fazendo normalmente o plural em -is, quer os nomes de final acentuado, quer os outros.

É evidente que, por mais importantes que sejam os factores sociais, estão submetidos aos imperativos do sistema linguístico, apenas actuando nos contextos em que este o permite. Assim, para além dos condicionamentos sócio-culturais que impulsionam uma mudança linguística, na determinação da sua racionalidade deverão também considerar-se as condições necessárias para a sua ocorrência. Weinreich, Labov e Herzog apontam para uma interacção das duas ordens de factores, sublinhando que "explanations which are confined to one or the other aspect, no matter how well constructed, will fail to account for the rich body of regularities that can be observed in empirical studies of language behavior" (Weinreich / Labov / Herzog 1975: 188). Assim, por exemplo, para a síncope de - $d$ - nas formas verbais de $2^{\mathrm{a}}$ pessoa do plural, foi determinante a sua posição intervocálica; por outro lado, a compatibilidade ou incompatibilidade dos sons na cadeia falada estiveram na origem dos diferentes ritmos evolutivos na passagem da vogal temática $u$ da terminação - $u d o$ à vogal temática $i$ da terminação participial moderna; e a presença de três vogais contíguas em formas de plural de alguns nomes, adjectivos e pronomes de lexema em - $l$, favoreceu a passagem da vogal temática a semivogal e consequente formação do ditongo. No entanto, a "adopção" e a "difusão" das novas variantes esteve, normalmente, associada a factores extralinguísticos específicos.

Um outro importante factor a considerar na explicação da mudança linguística é o processo de "nivelação analógica", cujos efeitos mais frequentes se dão na Morfologia. Uma mudança analógica traduz-se na substituição de uma forma menos "transparente" (Bynon 1981: 59), ou já não transparente para o falante, por outra nova, funcionalmente equivalente, cuja estrutura reflecte a do modelo. Assim, por exemplo, o progressivo apagamento da terminação - $u d o$ dos verbos da segunda conjugação, com consequente redução da alternância morfológica -udo -ido, deveu-se a um processo de nivelação cujo modelo deverá ter sido oferecido 
pelos particípios dos verbos de tema em $i$. Ora, é muito provável que os factores que favorecem qualquer mudança analógica sejam os mesmos que impulsionam a difusão de qualquer outra inovação linguística.

Antes de empreender qualquer divisão da língua em períodos, convém, contudo, salientar que ela deverá representar um compromisso entre vários pontos de vista e várias "línguas funcionais" (Coseriu 1981: 308), devendo, por isso, ter-se em consideração que fenómenos modernos alvoreceram em períodos marcadamente arcaicos e que, ao invés, fenómenos de sabor arcaico continuaram a persistir, ainda que sob novas roupagens, em fases modernas e contemporâneas. Daqui resultam, inequivocamente, consequências de relevo na delimitação dos termos a quo e ad quem dos marcos balizadores desses períodos: se, por um lado, é particularmente difícil datá-los com rigor, já que "as alterações lingüísticas não dependem do calendário nem do ano em que o século acaba ou começa” (Ali 1964: 8), por outro, será necessário operar com critérios de relativização, que é sempre correlata da heterogeneidade social que caracteriza qualquer comunidade de fala. E, se é verdade que qualquer mudança linguística se processa lentamente e a ritmos diversos consoante as épocas, não é menos verdade que essa mudança não data de um momento preciso simultaneamente para todos os fenómenos em estudo. Para além das diferentes "avaliações" sociais a que estiveram sujeitas as variantes arcaicas de cada fenómeno e que, de algum modo, foram responsáveis pelas assimetrias observadas nas suas evoluções, acrescem as dificuldades oferecidas pelos diversos ritmos com que a oralidade se fixou no sistema gráfico: se em alguns fenómenos a fixação escrita acompanhou desde muito cedo a propagação oral, em outros a oralidade levou muito mais tempo a espraiar-se no texto escrito.

\section{Percorrendo o corpus disponível}

2.1. Apesar de a documentação privada trecentista oriunda das províncias galegas apresentar sempre a manutenção da consoante $-d$ - nas formas verbais, tal facto não deve levar a pensar que a síncope era totalmente desconhecida em tal zona geográfica. De facto, a constatação de duas formas isoladas (Leixaame e ataame) na tradução galega da Crónica Geral e da Crónica de Castilla conduz a outra conclusão. As ocorrências inovadoras encontradas não seriam mais que "lapsos" do tradutor, que empregou as que já corresponderiam ao som que ele conhecia. Do que não parece haver dúvida é que a "adopção" destas formas em território galego começou em ambientes cultos, pois não se documentam formas de tipo moderno nos textos notariais privados da mesma época. No que diz respeito ao território português, propriamente dito, parece ter sido também a corte do rei Lavrador o grupo social que as adoptou e propagou. O polimorfismo desta variável morfológica está já documentado num tratado de Direito de finais do século XIII 
-Flores de Dereyto-, assim como numa carta dionisiana, relativamente coeva, voltando a surgir no texto da versão portuguesa da Primeyra Partida e numa cantiga de "escarnho e de mal dizer", do começo do século XIV. Quanto aos textos de carácter legislativo referidos, as formas verbais encontradas não só já não exibem a dental, como também já revelam o resultado da fusão das duas vogais idênticas. Mas a etapa da "selecção" parece ter-se processado apenas em finais do século XIV. Algumas abonações encontradas na documentação régia lavrada, essencialmente, na zona centro-meridional do país, a partir da década de 50, provam-nos igualmente que as formas sem - $d$ - eram já conhecidas da língua oral, provocando flutuações na escrita. Tais abonações testemunham, também, o delinear da formação de um "dialecto" que começaria a afirmar o seu prestígio. Quanto à zona setentrional do país (Entre-Douro e Minho), apenas temos notícia de uma forma sincopada num documento de D. João I, lavrado no Porto em 1398. Estas constatações obrigam, portanto, a rever as investigações feitas até ao momento, que apontam como termo a quo deste fenómeno, o primeiro quartel do século XV.

Diferente se afigura, também, o cenário quatrocentista, na documentação localizada a norte e a sul do rio Minho. Com efeito, na documentação privada galega registou-se apenas um exemplo esporádico de síncope e de crase (1426), só voltando a ocorrer a queda de $-d$ - num documento do último ano do século. Porém, no que à zona setentrional do nosso país diz respeito (região minhota), data de 1453 o primeiro exemplo encontrado da queda de $-d$-. Na documentação régia da zona centro-meridional, tudo leva a crer que a partir da década de 20 do século XV a variante conservadora caísse em desuso, na língua comum, ficando reservada a algumas zonas geográficas ou circunscrita aos idiolectos de alguns grupos sociais. Tal situação reflecte, portanto, a pressão que os modelos linguístico e gráfico iam exercendo sobre os notários ligados à corte bem como a formação de um "dialecto" mais prestigiado, porque socialmente mais cotado. Inequívoco é que a verdadeira "mutação" linguística ocorreu no reinado de D. João I, mais propriamente com a nova corte e a nova nobreza saídas da revolução de 1383-1385. A historiografia do século XV apresenta um mosaico multifacetado, que advém, essencialmente, da heterogeneidade da estrutura social em que as personagens se movem, e que se reflecte, naturalmente, na sua linguagem. É essa análise da linguagem no seu contexto social que parece não ter sido alheia a Fernão Lopes. À semelhança destas crónicas, também a Crónica do Condestabre e o Cancioneiro Geral provam que, tal como para qualquer fenómeno de mudança e de variação actualmente em curso, é possível traçar para o período medieval algumas coordenadas da Sociolinguística actual, estabelecendo correlações entre os processos linguísticos e os fenómenos sociais como a idade, o sexo, o nível sócio-cultural e o grau de distanciamento social entre os interlocutores. Foi essa correlação que originou, em certos autores, nomeadamente Fernão Lopes, alguns poetas do Cancioneiro Geral e em Gil 
Vicente, a formação de determinadas atitudes linguísticas, das quais o fenómeno -des é apenas um exemplo. E, se as mulheres são, neste domínio, mais conservadoras que os homens, foi provavelmente na boca de mulheres do Povo que as formas antigas se fizeram ouvir durante mais tempo, antes de caírem no esquecimento. $\mathrm{O}$ valor estilístico de $-d$-, feminino e popular, domina o seu aspecto arcaico, como o atestam as obras dos autores mencionados.

Importa não perder de vista as reservas colocadas pelos textos de carácter religioso e moralístico para a delimitação cronológica do fenómeno, uma vez que se cruzam neles, não só várias camadas linguísticas como diferentes proveniências regionais e sociais. Estes textos (quer no século XIV, quer no século XV, ou ainda no seguinte) oferecem, na generalidade dos casos, a mesma situação de conservadorismo, motivada, como se depreende, pela necessidade de aproximação aos textos sagrados originais. Exceptuam-se alguns afloramentos isolados de síncope da consoante, em textos copiados no século XV, meros "lapsos" de copistas que, com o objectivo de divulgação das obras junto do público substituíam, inconscientemente, as formas do seu original pelas que eles já usavam.

Em última análise, pode dizer-se que entre o momento em que as novas formas começaram a suplantar as antigas (finais do século XIII, inícios do século XIV) e o seu virtual desaparecimento na língua falada $\left(1536^{7}\right)$, decorreu um espaço de tempo onde poderão ter vivido quatro gerações sucessivas.

2.2. A substituição de -udo por -ido remonta a meados do século XIII, encontrando-se documentada, quer em fontes situadas na Galiza, quer em território português, e manifesta-se em todos os tipos textuais (foros régios, documentos notariais privados, leis gerais, textos literários, etc.) e em todo o tipo de verbos ${ }^{8}$. De facto, não se vislumbra, na análise efectuada no corpus ducentista, qualquer indício de uma possível co-variação das duas variantes participiais e certos factores de tipo social (a proximidade da corte, por exemplo), que façam pensar numa distribuição de formas antigas e modernas por diversos níveis sociolinguísticos. O que parece evidente é a proliferação de particípios modernos a partir de meados desse século, quer na província de Lugo, quer numa zona restrita da Beira Interior, muito próxima do reino de de Leão: Castelo Rodrigo. A passagem de /u/ a /i/ em sílaba tónica foi um fenómeno relativamente célere: tratou-se, efectivamente, de uma simples substituição de fonemas que, por não provocar alterações fonético-morfológicas relevantes, se propagou rapidamente, quer na língua oral, quer na língua escrita. Uma análise de conjunto do corpus analisado permite, contudo, distinguir, a partir

7 Referimo-nos à data da Floresta de Enganos de Gil Vicente.

8 Há formas participiais que, apesar de só em finais do século XIV ou mesmo no início do século XVI terem cedido definitivamente à evolução, exibem a terminação moderna já no século XIII (auido, recebido, retido, etc.). 
de meados do século XIV e particularmente na documentação régia e privada e na prosa cronística, três grupos de verbos que apresentaram diferentes ritmos evolutivos nas suas terminações participiais, decorrentes das afinidades combinatórias dos sons na cadeia falada9: verbos cuja terminação participial está precedida de fonema alveolar (/s/, /z/, /r/), dental (/d/ e /t/) ou palatal (/J/, /3/, / $\lambda /$ ): conoscer, cozer, constranger, entender, encher, meter, mexer, requerer, tolher, vender, etc.; verbos cuja terminação participial está precedida de fonema fricativo labiodental (/f/ e /v/) ou bilabial, quer se trate de fonema oclusivo, quer de fonema contínuo $(/ \mathrm{m} /, / \mathrm{p} / \mathrm{e} / \mathrm{b} /)$ : apremer, aver, dever, receber, romper, saber, sofrer, temer, etc.; verbos com duas vogais em hiato, resultantes da síncope de consoante intervocálica: caer, creer, leer, raer ('raspar', 'limpar'), teer, traer, veer, e seus compostos: conteer, descreer, manteer, perleer, proveer, etc. Face ao que foi exposto, parece importante concluir que, no que concerne a evolução de -udo para -ido e a sua propagação no tempo, estamos perante fenómenos de natureza diversa: os particípios do primeiro grupo não deixaram vestígios na língua de hoje, pois fixaram-se rapidamente na língua arcaica; os particípios dos $2^{\circ}$ e $3^{\circ}$ grupos deixaram marcas visíveis no português contemporâneo (cf. Temudo, apel., conteúdo, etc.), configurando, assim, fenómenos com acentuada projecção diacrónica. É, de facto, inquestionável que a propagação analógica das formas em -ido começou no primeiro grupo participial, registando-se, regularmente, a partir de meados do século XIV. No século XV as terminações deste tipo são já, de um modo geral, em -ido, sendo que, quando precedidas de da fricativa palatal / $3 /$ ou das oclusivas dentais (/t/ e /d/) surgem ainda em variação até meados desse século. Quanto ao segundo grupo participial, as formas modernas apenas começam a propagar-se no segundo quartel do século XV, generalizando-se nos últimos anos deste século. Efectivamente, os primeiros incunábulos apresentam já a vacilação entre as terminações arcaica e moderna. A forma participial que mais resistência ofereceu à mudança foi auudo. Um dos melhores representantes dessa coabitação das duas variantes é o texto do Tratado de Tordesilhas, que apresenta em variação "auidos e por auer" e "auudos e por auer". No século XVI apenas persistem nos textos os particípios arcaicos dos verbos creer, leer e teer (e seus compostos).

Importa, ainda, referir que as formas arcaicas de verbos do primeiro tipo eram, muito provavelmente já em meados do século XV, sentidas como formas de marcar pejorativamente os falantes que as actualizavam. Delas se serviu Fernão Lopes para ridicularizar algumas personagens castelhanas, pelas suas intervenções. Mas só decorridos cerca de 80 anos Gil Vicente conseguiria mostrar, pelo riso, as assimetrias sociais provocadas pelo franco progresso económico-cultural da era de Quinhentos. Para esse riso do público muito contribuiriam as formas arcaicas utilizadas pelos campo-

9 É sabido que os espectros vocálicos se modificam em contacto com as consoantes, condicionando a evolução do sistema fonético-fonológico de uma língua. 
neses: a forma creçudo provém, precisamente, da boca de uma mulher, que tenta justificar $a b$ absurdo o comportamento (pouco digno) da sua filha.

2.3. Remonta a meados do século XIII a generalização a ambos os contextos (proclítico e enclítico) das formas pronominais minha, tua e sua, que, eliminando progressivamente as átonas mha $(m a)$, ta e $s a$, começam a reunir em si a dupla função adjectiva e pronominal. Mas, se a cronologia do aparecimento da forma sua com função adjectiva é relativamente coincidente para a documentação notarial das áreas galega e portuguesa (década de 50 daquele século), parece ter sido ligeiramente mais tardio o desenvolvimento da consoante nasal palatal na variante mia, nos documentos portugueses, pese embora a escassez de fontes notariais que nos permitam extrair conclusões mais seguras. $\mathrm{O}$ uso destas formas em posição adjectiva era, no entanto, conhecido dos trovadores portugueses, que se serviam deste recurso para extrair os efeitos métricos reclamados por algumas composições. Assim, temos indícios no território português de que a adopção dessa variante moderna se fez por níveis sociolinguísticos. A partir da década de 70 do século XIII, a documentação notarial portuguesa de carácter privado e régio, exibe, todavia, a forma de "transição" mĩa, em variação com a forma mais arcaica $m h a$, coabitação que se prolonga nos textos até meados do século XIV, altura em que começa a surgir a forma adjectival minha. A partir desta altura inicia-se, assim, a etapa da "difusão" e, sobretudo a partir do $3^{\circ}$ quartel desse século, a da "selecção" ${ }^{10}$, processo que se poderá ter devido a diferenças entre os vários grupos dentro da(s) comunidade(s) de fala, eventualmente decorrentes de factores como a "idade" e o "estrato sóciocultural". O que interessa, no entanto, realçar é que o único contexto de ocorrência das formas de $1^{a}$ pessoa nos documentos notariais é em expressões deícticas ligadas ao acto da feitura do documento, de nítida feição formular. Neste contexto, é sabido, não reflectiria já os usos que delas fariam os falantes. É possível que ao entrar no século XV a percentagem de ocorrência das formas tónicas em contexto proclítico para as primeiras pessoas fosse idêntica à de $2^{\mathrm{a}}$ e $3^{\mathrm{a}}$, ou seja, cerca de $80 \%$. A partir da década de 40 do século XV já não se fazia distinção entre formas com função adjectiva ou pronominal, neste tipo de fontes.

Também ao nível da prosa literária, a situação linguística dos textos galegos revela um avanço significativo relativamente aos portugueses, exceptuando a Crónica Troyana, confeccionada por escribas procedentes de diferentes zonas dialectais. Basta comparar a versão galega da General Estoria, onde já não há distinção entre formas átonas e tónicas, com o Livro de Alveitaria de Mestre Giraldo (relativamente coevo ou pouco anterior), onde sua com função determinativa apenas representa $5,5 \%$, para visualizar

${ }^{10}$ Relembre-se que na concepção coseriana a "selecção" consiste no uso alternado das duas variantes. A flutuação entre variantes antigas e modernas no interior do mesmo texto regista-se, essencialmente, nos textos notariais de carácter privado e régio. Nos textos literários, a distribuição das modernas e antigas variantes no interior do mesmo texto, é, muitas vezes, de carácter funcional, reflectindo um tipo de variação de natureza estilística, contextual ou diafásica. 
tal assimetria. De facto, só nos finais do século XIV a prosa portuguesa evidencia, de forma definitiva, a generalização, a ambos os contextos, de minha, tua e sua. A prosa literária quatrocentista elimina completamente a variante arcaica da $1^{\mathrm{a}}$ pessoa, que parece ter sido alvo de uma estigmatização social mais acentuada que as de $2^{\mathrm{a}}$ e $3^{\mathrm{a}}$. Nas crónicas de Fernão Lopes encontra-se virtualmente extinta a variante átona $s a$ (saliente-se que esta forma surge usada como estereótipo ou marcador social na Crónica de D. João I, no discurso de uma abadessa "aleivosa" e "parenta da rainha", onde, curiosamente, também se regista a forma verbal arcaica leixade, e no Cancioneiro Geral ta e sa apenas sobrevivem por razões métricas. Antecipando o espírito satírico vicentino, é possível que Fernão Lopes, nascido numa época em que $s a$ e $t a$ entravam em franco declínio, as sentisse já como formas que poderiam marcar socialmente as suas personagens. Mas é, novamente, Gil Vicente quem delas extrai os melhores efeitos satíricos: camponeses, lavradores, velhas e judeus parece terem sido as personagens mais vitimadas pelos "marcadores sociais" ta, sa e enha.

2.4. Quanto ao último fenómeno, a escassez de abonações reflectindo a configuração actual do morfema do plural dos lexemas em - $l$ não deverá ser encarada como sintoma de uma evolução muito tardia no morfema em estudo, cuja evolução deve ter tido, na nossa opinião, uma cronologia na língua oral muito semelhante a outros fenómenos considerados iniciadores do português moderno. Parece ser este, de facto, o fenómeno "enganador", por excelência" ${ }^{11}$, na medida em que melhor do que qualquer outro evidencia a lentidão das passadas dadas pela grafia relativamente à evolução e à transformação da língua. Revelam uma notável precocidade os plurais de lexemas em $-l$ precedido de $a$ e de $e$ que possuem uma vogal a preceder a sílaba tónica (crueis, fieis, iguais, infieis, reais, etc.) e ainda de lexemas monossilábicos em $-l$, precedido de a (tais e quais, por exemplo). Esta celeridade evolutiva poderá dever-se, no primeiro caso, à dificuldade de actualização de três vogais silábicas que ficariam contíguas, após a síncope de - $l$-. A flutuação no uso dos plurais males e maes, verificada em muitas obras dos finais do século XIV e já inexistente na Crónica Geral de Espanha, poderá ser tida como indicador da mutação linguística observada, por essa altura, neste fenómeno. De facto, se o - $l$ - ressurgiu neste lexema para evitar a confusão com o advérbio mais $^{12}$, é porque maes e mais já se confundiam na pronúncia. Uma pista para o desaparecimento de -viis / -vis em proveito de -vees / -ves (a semivogal pode ter substituído a vogal temática ou ter-se desenvolvido, após a crase) parece poder encontrar-se no plural moviis que surge na parte I da Crónica de D. João I, mas já na variante movees na parte II da mesma obra.

${ }^{11}$ Relembre-se a sugestiva expressão de Ivo Castro: “o som já se apagou há muito e só o podemos conhecer por inferência, a partir de grafias que ora aspiram à transcrição fonética, ora não aspiram, tingindo de ambiguidades um relacionamento entre língua oral e língua escrita que é sempre desconfortável, quando não enganador" (Castro 1993: 97).

12 Segundo J. Joaquim Nunes, "o desejo de evitar a confusão, que naturalmente se daria com o advérbio mais, fez ressurgir o -l- que caíra [...]” (Nunes 1989: 229). 
Apesar de algumas limitações deste tipo de análise, como a falta de representatividade de um corpus que sobreviveu fortuitamente e que, por isso, escapa ao controlo do observador, julgamos pertinente esquematizar a evolução dos quatro fenómenos em algumas obras de carácter técnico, cronístico e religioso. Importa referir que a selecção destas obras, que, de modo geral, reflectem a norma de prestígio, decorreu apenas da necessidade de partir de um ponto de referência que veicule o maior índice de representatividade relativamente a todos os períodos e a todos os fenómenos estudados ${ }^{13}$. Observemos, pois, o gráfico:

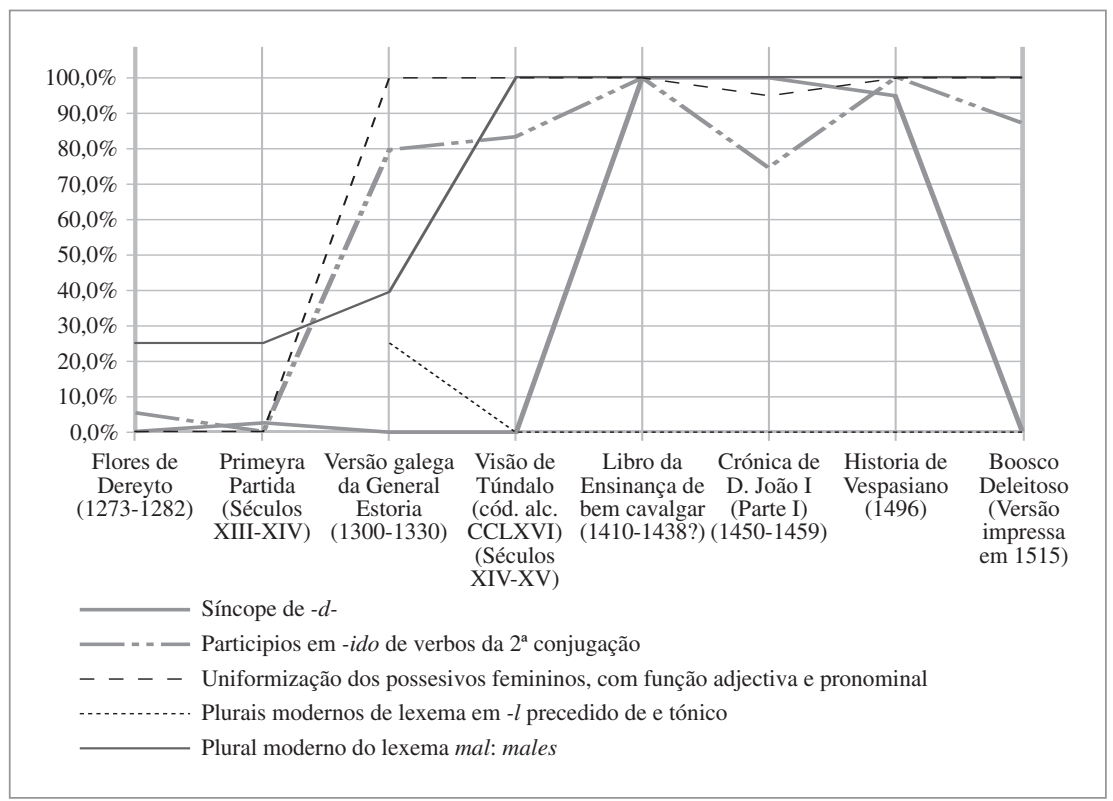

Gráfico $n^{\circ} 1$. Ritmos das mudanças nos quatro fenómenos estudados, ao longo do eixo diacrónico (sécu$\operatorname{los}$ XIII-XVI).

13 Assim, as variedades que coexistiram no espectro sócio-cultural medieval não deverão ficar obliteradas. Estamos, de facto, conscientes de que o diassistema linguístico medieval engloba igualmente os falares e discursos dos camponeses, dos pastores, dos mesteirais e homens do mar, mas, infelizmente, são insuficientes e surdos os fragmentos que se encontram nos discursos directos dos textos. Deles, talvez apenas Fernão Lopes nos tivesse deixado alguns ecos. É também evidente que não poderemos incluir no gráfico os dados fornecidos pela documentação notarial (privada e régia), dado o seu carácter fragmentário. Por outro lado, grande número de textos situados no período que medeia entre $1330 \mathrm{e}$ 1380 são, essencialmente, de carácter religioso, apresentando, por isso, a particularidade de constituírem, em grande parte dos casos, traduções do latim ou versões posteriores de originais escritos numa língua que já começava a parecer arcaica. Por essa razão, este período carece de representatividade no nosso gráfico. Refira-se ainda que, no que diz respeito aos plurais dos lexemas em $-l$, seleccionámos apenas os plurais modernos dos lexemas em $-l$ precedido de $e$ tónico, por ser o subsistema que mais inovações oferece. Poderá revelar-se esclarecedora, para os plurais modernos dos lexemas em $-l$ precedido de $a$, a evolução observada no plural do lexema mal, razão por que a incluímos. 
A variável morfológica que se revela mais rica em virtualidades é, sem dúvida, o morfema - des das formas verbais de $2^{\mathrm{a}}$ pessoa do plural, pois mais amplo se afigura o leque cronológico que medeia entre o momento da "adopção" das formas sem - $d$ - (a síncope representa $0,8 \%$ em Flores de Dereyto) e a sua extinção do texto escrito (o - $d$ - ocupa ainda $5 \%$ em História de Vespasiano e domina todo o Boosco deleitoso, cópia impressa em $1515^{14}$ ). Por não ter tido uma evolução linear, paulatina, deverá ser analisado atendendo ao cenário sociolinguístico e diatópico em que ocorre, aos processos de distribuição estilística ou diafásica e às virtualidades comunicativas que lhe subjazem, à caracterização das personagens que se movem no espaço textual, bem como ao tipo de autor que lhes dá forma. Parece-nos, pois, que mais importante que encarar o fenómeno de permanência ou de síncope de $-d$ como índice de conservadorismo ou de inovação tout court será enquadrá-lo na moldura diassistemática em que, cremos, qualquer língua histórica merece ser analisada, e verificar os efeitos pragmáticos resultantes da convivência plurissecular de formas antigas e novas. O que parece não oferecer dúvidas é a funcionalidade e a intencionalidade da preservação do $-d$-, enquanto "indicador" de certo tipo de personagens, em alguns contextos das crónicas de Fernão Lopes, o "cronista do Povo", em meados do século XV. Por este motivo, parece que a partir de 1450, as formas com - $d$ - já eram alvo de estigmatização nos meios cultos.

\section{Conclusões}

Uma visão de conjunto da evolução dos quatro fenómenos estudados revela, sem sombra de dúvida, que ao terminar o primeiro quartel do século $\mathrm{XV}$, a língua portuguesa, entendida como suporte da tradição literária, vestia já definitivamente os

${ }^{14}$ É interessante constatar, a este propósito, que na prosa religiosa medieval o - $d$ - intervocálico da $2^{\mathrm{a}}$ pessoa do plural das formas verbais sobreviveu até ao início do século XVI, eventualmente como tentativa de captação de uma aproximação ao arquétipo latino. A variedade de prestígio para a comunidade religiosa medieval parece, assim, não se ter identificado com a variedade standard, difundida pelos centros de poder.

Este facto vem provar que uma variedade (ou forma) standard não é conceptualmente o mesmo que uma variedade de prestígio. A standardização surge por razões funcionais, mediante os usos linguísticos nas funções administrativas pelos que detêm o poder político. Uma vez difundida a outras funções adquire o que normalmente se designa de "prestígio" no sentido em que é um instrumento ao serviço da mobilidade social dos falantes. O conceito de "prestígio" é, no entanto, diferente, uma vez que pode estar subjectivamente ligado a falantes, formas e variedades que poderão estar muito afastados, ou mesmo em conflito, com as formas da variedade standard. Curiosamente, nos mesmos textos em que o- $d$ - era preservado, a modernização linguística efectuou-se a nível do sistema de pronomes possessivos femininos e dos particípios passados dos verbos da $2^{\mathrm{a}}$ conjugação, cuja evolução foi muito mais célere, quer na língua oral, quer no texto escrito. O exemplo mais lídimo desta assimetria parece poder colher-se, precisamente, no Boosco deleitoso, impresso em 1515: se, no que concerne o - $d$ - intervocálico esta obra representa uma fase linguística muito mais antiga (uma vez que o - $d$ - se mantém sistematicamente), as formas dos possessivos femininos são as mesmas em contexto adjectival ou pronominal, e os particípios passados dos verbos da $2^{\mathrm{a}}$ conjugação terminam, normalmente, em -ido. Tal situação revela, indubitavelmente, uma diferente "avaliação" social das variantes antigas destas variáveis. 
trajes da modernidade. Se tivéssemos que escolher um marco histórico significativo para assinalar a verdadeira viragem do português arcaico para o português moderno, não hesitaríamos em apontar a revolução de 1383-85, momento que fez surgir, despoletada pela mobilidade sócio-geográfica do Povo e da empreendedora burguesia lisboeta, uma nova ordem social.

A documentação medieval portuguesa analisada ao longo das pesquisas efectuadas demonstra, claramente, que a mudança linguística esteve, de facto, associada a um momento histórico-político que desencadeou uma grande mobilidade populacional. Momentos de grande efervescência linguística foram também períodos que ficaram assinalados como etapas fundamentais da nossa história: as transformações políticas, sociais e económicas de finais de Trezentos, nomeadamente o abalo irreversível das estruturas feudais e o nascimento de uma nova ordem social caracterizada pela ascensão da burguesia, constituem factores externos de grande impacto na estrutura linguística. Como se depreende, a mutação linguística vem, necessariamente, acompanhada de uma etapa de variação na qual convivem as formas rivais. De uma maneira geral, a partir de 1350 as variantes modernas e as antigas começaram a conviver no interior do mesmo texto, excepto em fenómenos que adquirem uma feição peculiar decorrente da falta de correspondência entre o "oral" e o "escrito".

Assim, e não esquecendo o carácter diassistemático da língua, pode dizer-se que a fase arcaica dominou toda a primeira metade do século XIV, período em que se verificou a "adopção", relativamente esporádica e individual, das modernas variantes. A sua progressiva "difusão", cuja fixação escrita teve ritmos diferentes consoante os fenómenos, ocorreu entre 1350 e 1380, coincidindo com a liderança política de D. Fernando, sediado em Lisboa. Desde a revolução de 1383-85 estrutura-se, efectivamente, uma outra "conjuntura linguística", vivificada pelos novos quadros sócio-económicos: se exceptuarmos os textos de carácter religioso, em que a permanência de $-d$ - se fez sentir até começos do século XVI, verifica-se que a partir de finais do século XIV, o panorama linguístico do corpus analisado, no que concerne os fenómenos estudados, tem já muito mais de moderno do que de arcaico ${ }^{15}$.

Ainda que a variedade de prestígio estivesse já bem definida nos textos do primeiro quartel do século XV, a "selecção" continuou a processar-se até cerca de 1450, configurando, assim, uma fase de "transição da língua medieval para uma plataforma estável" (Castro 1991: 243). Revela-se determinante, nesta fase de transição, o papel desempenhado por D. João I e pelos Infantes de Avis na unificação e consolidação da língua, como laço de identidade nacional. Pela nossa parte, é a esta etapa da língua que vamos chamar a fase do "português médio" ou "pré-moderno",

\footnotetext{
15 A denominação de fase "arcaica média", dada por Evanildo Bechara à fase do português que se esten-
} de do século XV à primeira metade do século XVI, merece, portanto, ser repensada. 
antecipando, assim, significativamente, o termo ad quem que lhe foi fixado por Castro (1991: 243). Mas é, sem dúvida, com a prosa cronística de Fernão Lopes que a língua atinge a sua fase de maturidade; ou seja, quando se delineia o distanciamento necessário entre o momento de efervescência linguística que caracterizou o final do século anterior e o momento em que, já praticamente despida de particularismos, a língua se oferece como objecto de observação. A fase moderna da língua começa, precisamente, com a formação dessa consciência linguística, que se traduz na "avaliação" social dos falantes (escritores) relativamente a determinados traços, que aos seus olhos vão parecendo arcaicos. Quando, depois do acidente de Alfarrobeira, D. Afonso V sobe ao trono, pondo termo às crises e lutas que se vinham arrastando desde o século anterior, a língua parece entrar definitivamente nessa "plataforma estável"16. Do ponto de vista sócio- económico, essa "estabilidade" linguística acompanhou a inversão do rumo do país: as conquistas africanas, o triunfo do neo-senhorialismo, o começo da repercussão da expansão ultramarina na vida da Metrópole, bem como o adensar das redes sociais motivado pela ascensão da curva demográfica, foram decisivos para a consolidação da língua. Assim, na década de 80 do século XV, ao soprarem na cultura portuguesa os ventos do humanismo italiano, e com o estabelecimento, a uma escala transcontinental, do capitalismo comercial, favorecido pela nova rota do Cabo, pode dizer-se que estavam consumadas na língua portuguesa algumas transformações morfológicas, particularmente significativas para a periodização.

Finalmente, convém salientar o carácter artificial que qualquer divisão comporta, recordando, mais uma vez, a concepção de língua em constante devir e que adquire contornos mais definidos quando do presente se lança um relance pelo passado. Se é inegável que os alvores da modernidade se poderão entrever na língua dos trovadores, parece também não oferecer dúvidas que alguns traços arcaicos restaram, como marcas indeléveis, no português contemporâneo.

\section{Referências bibliográficas}

Ali, M. S. (1964): Gramática histórica da língua portuguesa. $3^{\mathrm{a}}$ edição melhorada e aumentada de Lexeologia e formação de palavras e Sintaxe do português histórico. Estabelecimento do texto, revisão, notas e índices pelo Prof. Maximiano de Carvalho e Silva (S. Paulo: Edições Melhoramentos).

Bynon, T. (1981): Lingüística histórica (Madrid: Gredos).

\footnotetext{
16 Importa, todavia, ter em conta que adoptámos esta expressão neste contexto, referindo-nos apenas aos fenómenos estudados. Naturalmente que, mesmo depois do século XVI, a língua vai sofrendo alterações importantes, nomeadamente nos domínios do vocalismo e do consonantismo.
} 
Carvalho, M. J. (1999): “A alomorfia no plural dos nomes de lexema em -l: um estudo de morfologia histórica portuguesa”, em Direcção da Associação Portuguesa de Linguística (org.): Actas do XIV Encontro da Associação Portuguesa de Lingüística. Vol. I: 265-281 (Coimbra: Gráfica de Coimbra Lda.).

Carvalho, M. J. (2001): “Cronologia(s) da substituição da terminação participial -udo por -ido no português medieval (sécs. XIII-XVI)", Revista Portuguesa de Filologia, 23: 381-409.

Carvalho, M. J. (1996): Do Português arcaico ao Português moderno: contributos para uma nova proposta de periodização. Tese de Mestrado elaborada no âmbito do "Programa Intervenção Operacional Praxis XXI" e apresentada à Faculdade de Letras de Coimbra (inédita).

Carvalho, M. J. (2000): “O morfema -des na história da língua portuguesa: uma abordagem segundo a metodologia da Sociolinguística histórica", em Englebert, A. / Pierrard, M. / Rosier, L. / Raemdonck, D. Van (eds.) (2000): Actes du XXII ${ }^{\text {è }}$ Congrès International de Linguistique et de Philologie Romanes (Bruxelles, 23 28 juillet 1998). Vol. II: 65-74 (Tübingen: Max Niemeyer Verlag).

Carvalho, M. J. (1999): "Sociolinguística histórica: estatuto, metodologia e problemas". Separ. da Revista Portuguesa de Filologia, 22: 1-18.

Castro, I. (com a colaboração de R. Marquilhas e J. Léon Acosta) (1991): Curso de história da língua portuguesa (Lisboa: Universidade Aberta).

Castro, I. (1993): “A elaboração da língua portuguesa, no tempo do Infante D. Pedro", en Actas do Congresso Comemorativo do 61 Centenário do Infante D. Pedro (25 a 27 de Novembro de 1992) = Biblos, 69: 97-106.

Coseriu, E. (1981): Lecciones de Lingüística general (Madrid: Gredos).

Godinho, V. Magalhães (1968): Ensaios. II. Sobre História de Portugal (Lisboa: Sá da Costa).

Maia, C. de Azevedo (1997) [1986]: História do galego-português. Estado linguístico da Galiza e do Noroeste de Portugal desde o século XIII ao século XVI (Com referência à situação do galego moderno) (Lisboa: Junta Nacional de Investigação Científica e Tecnológica / Fundação Calouste Gulbenkian).

Maia, C. de Azevedo (1994): "O Tratado de Tordesilhas: algumas observações sobre o estado da língua portuguesa em finais do século XV". Separ. de Biblos. Revista da Faculdade de Letras, 70: 33-91.

Maia, C. de Azevedo (1999): "Periodização na história da língua portuguesa: status quaestionis e perspectivas de investigação futura" em Eberhard, G. / Hundt, C. / Schönberger, A. (eds.) (1999): Estudos de história da língua portuguesa: 2139 (Frankfurt am Main: TFM). 
Maia, C. de Azevedo (1995): "Sociolinguística histórica e periodização linguística. Algumas reflexões sobre a distinção entre 'português arcaico' e 'português moderno"”. Separ. de Diacrítica, 10: 5-11.

Nunes, J. J. (1989) [1919]: Compêndio de gramática histórica portuguesa. (Fonética e morfologia) (Lisboa: Livraria Clássica Editora).

Remacle, L. (1948): Le problème de l'ancien wallon (Liège: Faculté de Philosophie et Lettres).

Romaine, S. (1988): "Historical Sociolinguistics. Problems and Methodology", em Ammon, U. / Dittmar, N./ Matheier, K. J. (eds.) (1988): Sociolinguistics. Vol. II: 1452-1469 (Berlin / New York: Walter de Gruyter).

Weinreich, U. / Labov, W. / Herzog, M. I. (1975) [1968]: Empirical Foundations for a Theory of Language Change, em Lehmann, W. P. / Malkiel, Y. (eds.) (1975): Directions for Historical Linguistics. A Symposium: 95-188 (Austin and London: University of Texas Press). 